\title{
Difficult removal of a deep implant using a traditional removal method
}

I read with great interest the correspondence from Dr Kandiyil ${ }^{1}$ and Dr Shepherd ${ }^{2}$ about implant removal in the July Journal and also Dr Menon's ${ }^{3}$ letter in the October issue.

Journal readers might be interested to hear about a recent patient of ours, who was referred to the central family planning (FP) clinic from a peripheral FP clinic for deep implant removal. This 27-year-old woman presented with a 3-month history of irregular per vagina bleeding, having had an implant in situ for 3 years. The deep implant was not palpable from the time of insertion by either the patient or medical professionals. The implant was located deep under subcutaneous fat, as the patient had gained a significant amount of weight since the time of implant insertion.

On examination the implant had migrated $2 \mathrm{~cm}$ from the point of insertion towards the axilla and to the bottom of the groove between the biceps and triceps. The exact position of the implant was determined using a transvaginal ultrasound probe.

Lidocaine $2 \%$ with adrenaline was used as local anaesthesia and to reduce 
bleeding. A transverse incision (4 mm) was made through the previous scar. After a few attempts with the left middle finger to lift up and move the proximal end of the implant, it was finally successfully moved towards the skin in the direction of the incision.

The implant was removed using a traditional technique whereby pressure was applied to the proximal end of the implant (using the left middle finger again) and it was pushed along the insertion canal towards the insertion scar, where a removal incision was made. This allowed the migrated implant to be pushed laterally from the groove between the biceps and triceps. The insertion canal was re-used to move the migrated implant superiorly approximately $1.5 \mathrm{~cm}$ back along the insertion canal to the insertion scar.

After a few attempts the implant was successfully removed by applying additional pressure from the thumb and index fingers of the clinician's left hand to stretch the incision area and to locate the damaged end of the implant at the incision and to straighten the bent end. Continuous pressure with the left middle finger was applied to the proximal end of the implant, pushing it towards the insertion scar in accordance with the traditional method. The main difficulty experienced during the removal process was locating the distal end of the implant at the incision, on account of the implant being bent approximately $7 \mathrm{~mm}$ from its distal end, as was suspected during the removal procedure and confirmed after removal.

In conclusion, the traditional technique can be appropriate for deep implant removal and a transvaginal ultrasound probe can be used to confirm the position of a deep implant in an FP setting. Using lidocaine $2 \%$ with adrenaline is useful to reduce bleeding.

Lyubov Matytsina-Quinlan, PhD, DFSRH

Specialty Doctor in Family Planning and Sexual Health, East Cheshire Centre for Sexual Health, Macclesfield District General Hospital, Macclesfield, UK; lquinlan@nhs.net

Competing interests None.

J Fam Plan Reprod Health Care 2013:39:64-65. doi:10.1136/jpprhc-2012-100523

\section{REFERENCES}

1 Kandiyil VN. Easy method for Implanon ${ }^{\circledR}$ removal. J Fam Plann Reprod Health Care 2012;38:207-208.
2 Shepherd DJ. Self-removal of a contraceptive implant. J Fam Plann Reprod Health Care 2012;38:208.

3 Menon K. Implanon ${ }^{\circledR}$ removal technique. J Fam Plann Reprod Health Care 2012;38:271-272. 